[Original Article]

Received August 03, 2017

Revised August 19, 2017

Accepted August 23, 2017

${ }^{\dagger}$ Corresponding author

(mjapark@hanyang.ac.kr)

ORCID

Taejin Kim

http://orcid.org/0000-0002-3552-597X

Jeong Seon Sang

http://orcid.org/0000-0002-3382-161X

Myung-Ja Park

http://orcid.org/0000-0001-8816-0049

This paper is a part of a master's thesis.

\section{Fabric color and color difference recognized by smartphone display during mobile shopping \\ - Focused on instrument analysis method -}

Taejin Kim, Jeong Seon Sang and Myung-Ja Park ${ }^{\dagger}$

Dept. of Clothing and Textiles, Hanyang University, Korea

\begin{abstract}
Mobile shoppers have encountered frequent color mismatch in the products that they have purchased, as they can only rely on their sense of sight. Therefore, fabric color and color difference recognized by smartphone display during mobile shopping were studied using instrument analysis method. It aimed to gather precise information on actual fabric color understanding of the mobile shoppers purchasing textile products. Three smartphones were selected from LG, Samsung, and Apple companies, and four colors were researched (red, yellow, green and blue) to both polyester and wool test fabrics for color analysis though color measuring instruments. The results from the spectrophotometer indicated that the color coordinate location of smartphone fabric color is similarly distributed regardless of the type of fabric. The Samsung smartphone displays a relatively high color chroma (especially on red-colored fabric) regardless of the type of fabric due to a high color reproduction range. In contrast, the LG smartphone, which has high color temperature, displays high color chroma on the blue colored fabric with a significant color mismatch between the actual fabric color and smartphone fabric color. From the results of this study, issues related to mobile shopping can be addressed through an analysis of the products sold, the smartphone's color representation, and user understanding.
\end{abstract}

Keywords: mismatch(색상 불일치), smartphone(스마트폰), mobile shopping(모바일 쇼 핑), color difference(색차), display(화면)

\section{Introduction}

스마트폰은 초고속 무선 인터넷을 사용하여 장소의 제약 없이 이동 중에 인터넷 서비스를 이용할 수 있는 장점으로 $\mathrm{PC}$ 를 대신할 수 있는 기기로 자리 잡았다. 따라 
서 기존 온라인 쇼핑을 대체하여 그 비중이 점차 증 가하고 있으며, 온라인 쇼핑 업체들도 모바일 웹 또 는 앱을 이용한 모바일 쇼핑 서비스를 강화하기 시작 하였고, 지속적인 서비스 이용자들의 유입으로 그 비 중도 날로 커지고 있다(The Korea chamber of commerce \& industry, 2013; Statistics Korea, 2014).

모바일 화면은 제조 방식과 그 특성에 따라 색을 표 현하는 색 재현율이 상이하며, 스마트폰에 따라 같은 색을 다르게 표현할 수 있는 문제가 발생할 수 있기 때문에, 모바일 쇼핑 시 제품의 색상 차이가 나타나 게 된다. 모바일 쇼핑은 직접 제품을 확인하고 구매 하지 못하는 온라인 쇼핑의 한계점으로 소비자는 제 품을 직접 보고 판단할 수 없기 때문에, 쇼핑몰 또는 쇼핑 앱에서 제공하는 정보에 의존하여 제품을 구매 해야 한다(Yoh, 2011). 따라서 치수, 소재 재질감, 색 상, 혼용율 불일치, 봉제 불량, 배송문제 등 소비자 불 만 문제가 발행하고 있다(Kim, 2012). 모바일 쇼핑 역시 온라인 쇼핑과 유사한 문제점을 가지고 있다.

스마트폰이나 PC 화면을 통해서 보는 쇼핑의 문제 점에 관한 선행연구를 살펴보면, Park and Stole(2002) 은 패션제품 구입시 소재, 질감, 색상, 사이즈 정보가 정확하지 않다고 하였고, Korea Consumer Agency(2005) 는 제품의 불량이나 색상 차이 등의 외관에 관한 소 비자 불만이 높게 나타났다고 하였다. $\operatorname{Kim}(2007)$ 은 온라인으로 제품을 구매시 구매결정에 미치는 요인 으로 디자인, 색상, 소재의 일치가 중요하다고 했으며 남성소비자에 비해 여성소비자가 색상에 대한 불만 이 많다고 하였다. $\operatorname{Kim}(2012)$ 는 온라인 쇼핑으로 제 품을 구매할 때 디자인과 색상의 차이가 청소년들이 온라인 쇼핑을 할 때 가장 크게 지각하는 위험요소라 고 하였다. 특히 제품의 소재와 색상의 불일치가 소 비자들이 제품 구매 시 느끼는 위험지각 요인으로 나 타났다(Cho, Lim, \& Lee, 2001; Yun \& Kweon, 2003).

현재 상용화되고 있는 모바일 화면은 크게 $\mathrm{LG}$ 의 IPS와 Samsung의 AMOLED로 나눌 수 있다. IPS는 $\mathrm{LCD}$ 의 시야각과 색감을 개선시킨 화면이며, $\mathrm{AMOLED}$ 는 자체적으로 발광하여 색을 표현하는 유기발광 다 이오드를 사용한 화면이다. IPS는 기존 LCD계열의 화면으로 색역이 웹 표준인 sRGB 유사하기 때문에 색재현율이 우수할 뿐만 아니라, 시야각도 우수하여 현재 $\mathrm{TV}$, 스마트폰, 모니터 등 주요 화면에 주력으로
사용되고 있다. AMOLED는 IPS를 대체할 수 있는 차세대 화면으로 최근 주목받고 있는 화면으로써 IPS 의 색역보다 넓기 때문에 많은 색을 표현할 수 있으 며, 상대적으로 선명하고 화사한 색감을 느낄 수 있 다. 또한 화면 구동 시 백라이트가 필요한 IPS와 달리 $\mathrm{AMOLED}$ 는 자기발광성이 있는 유기발광 다이오드 를 사용하여 색을 표현하기 때문에, 저전력 구동이 가 능하고, 플렉서블(flexible) 화면과 같은 신기술 접목 이 가능하여 미래형 화면으로 주목받고 있다(Kim, Shin, \& Lee, 2014).

한편, 화면은 제조 공정, 화면 종류와 특성에 따라 색차가 상이하게 나타나는데, 색차가 나타나는 이유는 여러 요인이 복합적으로 작용하여 나타난다. 여러 요 인 중 색재현율, 휘도, 명암비를 말할 수 있다. AMOLED 와 IPS는 구동원리 및 그 특성의 차이가 크기 때문에 각각의 장단점이 존재하며, 사용자의 선호도 또한 상 이하게 나타나는데, 모바일 화면과 관련된 선행연구 를 살펴보면, IPS의 색재현율은 웹 표준인 $\mathrm{sRGB}$ 와 유사하고, 푸른색 계열의 색들이 실제보다 진하게 표 현된다고 하였으며, $\mathrm{AMOLED}$ 는 $\mathrm{sRGB}$ 의 색역의 약 $136 \%$ 로 나타나 색이 과하게 표현될 수 있다고 하였 다(Kim, Shin, \& Lee, 2014).

화면의 주관적 평가 실험을 진행한 Park, Lee, and $\mathrm{Ha}(2008)$ 의 연구에 의하면, LCD가 AMOLED에 비 해 사람들에게 자연색 재현이 우수하게 인식되는 것 으로 나타났으며, 채도가 높고 선명한 색은 상대적으 로 색재현율이 넓은 $\mathrm{AMOLED}$ 를 우수한 것으로 인식 하였다. 즉, $\mathrm{LCD}$ 의 경우, 사실적이고 자연스러움을 잘 표현하지만 색역이 좁기 때문에, 채도가 낮고 색을 다 양하게 표현하지 못한다고 하였으며, AMOLED는 색 의 표현이 선명하고 화사하기 때문에, 깨끗한 느낌이 지만 색역이 넓어 색이 과장되게 표현되며, 실제의 느낌보다는 부자연스럽게 표현된다고 하였다.

Lee(2013)는 광원색에 따라 직물색의 느낌이 상이 하다고 하였는데, 빨간색과 노란색은 $\mathrm{A}$ 광원 환경에 서 색의 강조효과가 있었고, 파란색은 $\mathrm{F}$ 광원 환경에 서 색의 강조효과가 있었으나, 초록색은 광원에 의한 색인상 차이가 미미한 것으로 나타났다. Choi and Lee (2006)의 연구에서도 광원에 따라 직물색의 이미지가 다르게 나타난다고 하였으나, 노란색의 경우 광원에 따른 차이가 없다고 하였다. 또한 전반적으로 주광 
(daylight)인 $\mathrm{D}_{65}$ 상용 광원 환경에서 관찰한 직물색 의 이미지 평가가 좋게 나타났다.

이상에서 살펴보면, 화면을 통해 인식되는 직물의 색재현에 관한 선행연구가 미흡하였고, 특히 모바일 화 면 직물색의 색재현에 관한 연구는 더욱 부족하였다. 따라서 본 연구에서는 국내 주요 스마트폰 제조사의 스마트폰을 대상으로 전문 측색기기를 통하여 직물 색 상 차이를 정량적으로 분석하여, 실제 직물색과 유사 도 정도를 알아보고, 스마트폰으로 인지되는 직물과 실 제 직물색과의 차이를 알아보아, 최종적으로 모바일 쇼핑 의류제품의 소비자에게 실제 직물색 정보를 정확 히 제공하여 모바일 쇼핑 시 색상 불일치로 인한 소비 자 불만과 반품 현상을 감소시키는 데 그 목적이 있다.

\section{Experiment}

\section{Materials and instruments}

\section{1) Test fabrics}

실험에 사용한 시료직물은 섬유종류, 직물조직, 표 면가공, 두께, 용도 등에 차이가 있고, 재질감이 전혀 다른 직물로 선정하였다. 섬유조성은 양모 $100 \%$ 와 폴 리에스터 $100 \%$ 두 종류이며, 섬유 별로 4 가지 기본색 (빨강, 노랑, 파랑, 초록)을 선택하여 총 8종의 직물을 실험에 사용하였다. 〈Table 1〉은 시험에 사용한 실제 직물 특성이다. 폴리에스터 직물은 두께가 $0.22 \mathrm{~mm}$ 로 얇고 표면이 매끈한 입체감이 적은 평직물이었으며, 양모직물은 두께가 $1.62 \mathrm{~mm}$ 로 상대적으로 두꺼웠으 며, 표면 기모가공 처리가 되어 직물 표면의 입체감 이 나타났다.

한국산업표준 KS A 0011(물채색의 이름: Korean

$<$ Table 1> Characteristics of the test fabrics

\begin{tabular}{c|c|c}
\hline Fiber & Polyester 100\% & Wool 100\% \\
\hline Fabric & Taffeta & Doeskin \\
\hline Thickness & $0.22 \mathrm{~mm}$ & $1.62 \mathrm{~mm}$ \\
\hline Weave & Plain & Satin \\
\hline Property & $\begin{array}{c}\text { Filament yarn } \\
\text { smooth surface }\end{array}$ & $\begin{array}{c}\text { Staple yarn, napping } \\
\text { Hairy, soft, bulky }\end{array}$ \\
\hline Use & Outdoor wear & Winter coat \\
\hline
\end{tabular}

Agency for Technology and Standards, 2010)과 공공 디자인 색채표준 가이드 2009(Korean Agency for Technology and Standards, 2009)를 참고하여 직물 색과 그에 대응하는 $\mathrm{L}^{*} \mathrm{a} * \mathrm{~b}$ *값을 기준으로 선정한 후, 기준 색의 $\mathrm{L}^{*} \mathrm{a} \mathrm{b}^{*}$ 값과 가장 유사한 직물을 구매하였다. 직 물의 크기는 실험 스마트폰 중 화면 크기가 가장 작 은 $($ 약 $50 \times 90 \mathrm{~mm})$ Apple사의 화면 크기와 동일하게 재단하여 사용하였다. 〈Table 2)는 실험에 사용한 직 물의 색상을 정리한 것으로 실험 직물 색과 기준 색 을 비교하여 사진으로 제시하였고, 객관적인 색 측정 을 위해 Macbeth사의 color-eye 3000 분광광도계를 사용하여 $\mathrm{L} * \mathrm{a} * \mathrm{~b} *$ 값을 측정하였다. 분광광도계 측색 조건은 $\mathrm{D}_{65}$, 시야각도는 $2^{\circ}$ 로 설정하였다.

〈Fig. 1〉은 Table 1 의 a*b* 값을 사용하여 표준색 과 직물색의 차이를 정확한 위치로 파악할 수 있도록 각각 좌표로 나타낸 것이다. $a * b *$ 좌표는 표준색 좌 표와 실험 직물 색 좌표의 비교를 위해 같은 영역에 표시하였으며, 영역안의 원은 표준색 좌표이고, 삼각 형은 실험 직물 색 좌표이다. 수집된 많은 직물 중에 서 KS 표준색과 가장 유사한 직물을 선정했으나, 모 든 색상에서 조금씩 색차를 보였다.

\section{2) Test smartphones}

실험에 사용한 스마트폰은 ATLAS 리서치의 2013 년 국내 휴대폰 판매 동향(ATLAS Research \& Consulting, 2014) 리포트를 참고하여 최종 실험용 스마트 폰으로 선정하였다. 선정한 스마트폰은 2013년 하반기 제조사별 판매순위가 높았던 제품으로써 각각의 제조 사와 모델은 LG의 G2, Samsung의 Galaxy S4 LTE-A, Apple의 iPhone $5 \mathrm{~S}$ 였다. 각각의 스마트폰에 사용된 화 면 특성은 상이하였으며, LG와 Apple은 IPS를, Samsung은 AMOLED를 사용하고 있었고, 화면 휘도는 Apple이 $574 \mathrm{~cd} / \mathrm{m}^{2}$ 로 가장 높았으며, $\mathrm{LG}\left(515 \mathrm{~cd} / \mathrm{m}^{2}\right)$, Samsung $\left(300 \mathrm{~cd} / \mathrm{m}^{2}\right)$ 순서로 휘도가 높았다(Table 3).

\section{3) Instruments for color measurement}

기기분석에 의한 측색 평가는 분광휘도 색차계(Konica Minolta사의 CA-1000)를 이용하여 실제 직물과 스마트폰으로 보이는 직물을 측색하였다.

\section{Measurement methods}

스마트폰 안에 있는 직물의 색상을 측정하기 위해 
$<$ Table 2> Colors of the test fabrics

\begin{tabular}{|c|c|c|c|c|c|}
\hline \multirow{2}{*}{ Fiber } & \multirow{2}{*}{ Color } & \multirow{2}{*}{$\begin{array}{l}\text { KS Standard color } \\
\left(D_{65}\right)\end{array}$} & \multirow{2}{*}{$\begin{array}{l}\text { Test fabric } \\
\text { (measured) }\end{array}$} & \multicolumn{2}{|c|}{ Color $\left(\mathrm{L}^{*}\right)$} \\
\hline & & & & Standard & Measured \\
\hline \multirow{4}{*}{$\begin{array}{c}\text { Polyester } \\
100 \%\end{array}$} & Red & & & $\begin{array}{l}40.51 \\
66.31 \\
46.13\end{array}$ & $\begin{array}{l}41.37 \\
55.65 \\
35.11\end{array}$ \\
\hline & Yellow & & & $\begin{array}{l}86.26 \\
-1.69 \\
96.59\end{array}$ & $\begin{array}{l}86.32 \\
-5.46 \\
72.48\end{array}$ \\
\hline & Green & & & $\begin{array}{r}51.43 \\
-63.50 \\
26.68\end{array}$ & $\begin{array}{r}55.15 \\
-42.36 \\
23.86\end{array}$ \\
\hline & Blue & & & $\begin{array}{r}51.19 \\
-6.78 \\
-47.25\end{array}$ & $\begin{array}{r}40.36 \\
6.77 \\
-45.30\end{array}$ \\
\hline \multirow{4}{*}{$\begin{array}{l}\text { Wool } \\
100 \%\end{array}$} & Red & & & $\begin{array}{l}40.51 \\
66.31 \\
46.13\end{array}$ & $\begin{array}{l}42.42 \\
60.43 \\
35.04\end{array}$ \\
\hline & Yellow & & & $\begin{array}{l}86.26 \\
-1.69 \\
96.59\end{array}$ & $\begin{array}{l}82.21 \\
-3.90 \\
83.15\end{array}$ \\
\hline & Green & & & $\begin{array}{r}51.43 \\
-63.50 \\
26.68\end{array}$ & $\begin{array}{r}32.99 \\
-39.88 \\
8.89\end{array}$ \\
\hline & Blue & & & $\begin{array}{r}51.19 \\
-6.78 \\
-47.25\end{array}$ & $\begin{array}{r}30.16 \\
2.58 \\
-32.45\end{array}$ \\
\hline
\end{tabular}
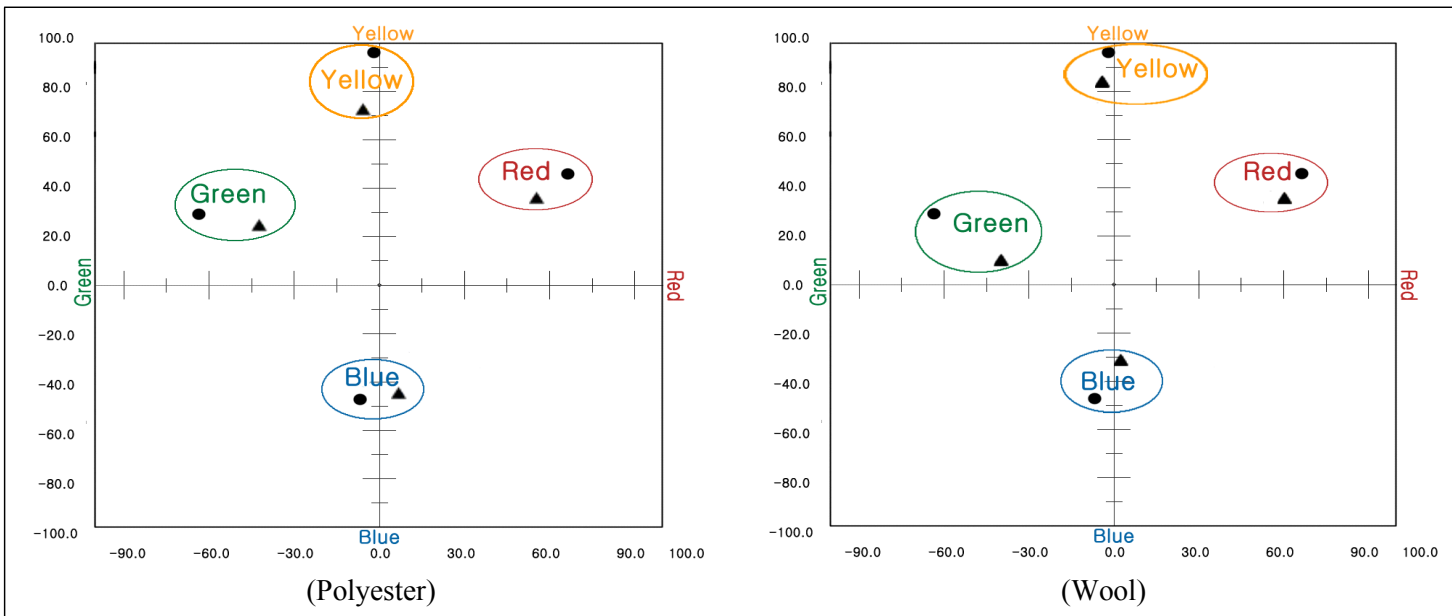

KS Standard color,

A Colors of the test fabrics

<Fig. 1> Color coordinate of the test fabrics 
$<$ Table 3> Characteristics of the test smartphones

\begin{tabular}{|c|c|c|c|}
\hline \multirow[t]{2}{*}{ Model } & $\cdots \overline{-1}$ & 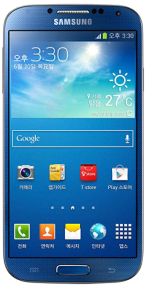 & 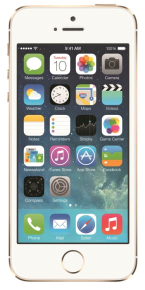 \\
\hline & $\mathrm{G} 2$ & $\begin{array}{c}\text { Galaxy S4 } \\
\text { LTE-A }\end{array}$ & iPhone $5 \mathrm{~s}$ \\
\hline Manufacturer & LG & Samsung & Apple \\
\hline Release date & Aug., 2013 & Jul., 2013 & Oct., 2013 \\
\hline Color temp. & $8000 \mathrm{~K}$ & $7100 \mathrm{~K}$ & $7200 \mathrm{~K}$ \\
\hline Max. brightness & $515 \mathrm{~cd} / \mathrm{m}^{2}$ & $300 \mathrm{~cd} / \mathrm{m}^{2}$ & $574 \mathrm{~cd} / \mathrm{m}^{2}$ \\
\hline Panel & IPS & AMOLED & IPS \\
\hline
\end{tabular}

서는 먼저 직물을 사진으로 찍어 스마트폰에 저장하 였다. Cannon 500D DSLR 카메라를 사용하였으며, 동 일 환경, 동일 거리 $(50 \mathrm{~cm})$ 에서 시료 직물의 촬영이 진 행되었다. 촬영 환경은 내부가 무채색 명도 N7로 조 성된 $60 \times 90 \times 60 \mathrm{~cm}$ 크기의 부스를 제작하여 이용하였 고, 부스 내부에 직물을 거치할 수 있는 $45^{\circ}$ 경사각 거치대를 추가로 제작하여 직물을 촬영하였다. 촬영 시 주변 광원은 최대한 차단하여 주변광원 효과를 상 쇄시킨 후 주광(day light)인 $\mathrm{D}_{65}$ 상용 광원을 주 광원 으로 이용하여 직물을 촬영하였다.

\section{Results \& Discussion}

\section{Comparison of fabric colors through naked} eyes and the smartphones

분광휘도색차계를 이용하여 실제 직물과 스마트폰 직물 색상을 측정한 결과는 다음과 같다(Table 4). 측 정된 색상 $\left(\mathrm{L}^{*} \mathrm{a} * \mathrm{~b} *\right)$ 데이터의 수치적 결과의 이해를 돕기 위해 X-rite사의 color I-control 소프트웨어를 이 용하여 측정결과의 수치를 색으로 재현하여 색차를 비교할 수 있도록 나타내었다(Table 5, Table 6).

〈Fig. 2〉와 〈Fig. 3〉은 측정 데이터〈Table 4〉의 $\mathrm{a}^{*} \mathrm{~b}$ *좌표로 나타낸 것이다. 좌표 위치를 통해 색상 및 채도를 확인할 수 있으며, 좌표의 a*가 ‘-’일수록 선명한 초록에, '+'일수록 선명한 빨강에 가까운 색이 다. 또한 b*가 ‘-’일수록 파랑에, b*이 ‘+'일수록 노랑 에 가까운 색을 의미한다. 먼저 실제 직물 색상좌표 와 스마트폰 색상좌표 분포를 분석하였다.

폴리에스터 직물은 모든 색상에서 스마트폰 직물과 실제 직물과의 색상 차이가 나는 것을 확인할 수 있 었다. 그 중 빨간색은 a*가 '+'경향을 보이고 있어 선 명한 빨강을 나타냈는데, 그중에서도 Samsung이 가장 크게 나타났다. 이와 반대로 노란색은 모든 스마트폰 직물 색상 좌표가 실제 직물 색상 좌표에 비해 $a^{*}$ 가 ‘-’경향을 보이고 있어 실제 직물 색상보다 초록이 표 현되는 색으로 치우쳐 있었다. 초록색은 스마트폰 직 물과 실제 직물의 색상이 가장 유사하게 나타났으며,

$<$ Table 4> Fabric colors through naked eyes and the smartphones

\begin{tabular}{|c|c|c|c|c|c|c|c|c|c|c|c|c|c|}
\hline \multirow[t]{2}{*}{ Fiber } & \multirow[t]{2}{*}{ Color } & \multicolumn{3}{|c|}{ Through naked eyes } & \multicolumn{3}{|c|}{$\begin{array}{c}\mathrm{LG} \\
(\mathrm{G} 2)\end{array}$} & \multicolumn{3}{|c|}{$\begin{array}{c}\text { Samsung } \\
\text { (Galaxy S4 LTE-A) }\end{array}$} & \multicolumn{3}{|c|}{$\begin{array}{c}\text { Apple } \\
\text { (i phon5s) }\end{array}$} \\
\hline & & $\mathrm{L}^{*}$ & $a^{*}$ & $\mathrm{~b}^{*}$ & $\mathrm{~L}^{*}$ & $a^{*}$ & $b^{*}$ & $\mathrm{~L}^{*}$ & $a^{*}$ & $b^{*}$ & $\mathrm{~L}^{*}$ & $a^{*}$ & $b^{*}$ \\
\hline \multirow{4}{*}{$\begin{array}{l}\text { Poly- } \\
\text { ester }\end{array}$} & Red & 46.91 & 59.46 & 34.79 & 47.57 & 64.71 & 41.90 & 55.78 & 81.84 & 52.87 & 51.01 & 66.32 & 41.05 \\
\hline & Yellow & 94.64 & -9.69 & 77.79 & 94.75 & -24.08 & 80.83 & 99.64 & -16.56 & 88.58 & 97.32 & -17.36 & 66.92 \\
\hline & Green & 65.53 & -45.86 & 27.74 & 73.69 & -42.71 & 26.95 & 77.42 & -46.50 & 23.24 & 77.47 & -34.34 & 19.79 \\
\hline & Blue & 46.78 & 6.93 & -48.46 & 47.71 & 35.58 & -69.66 & 53.97 & 15.16 & -67.87 & 56.82 & 16.82 & -57.20 \\
\hline \multirow{4}{*}{ Wool } & Red & 49.30 & 65.06 & 29.38 & 47.98 & 71.07 & 52.37 & 57.35 & 91.03 & 62.56 & 52.30 & 73.89 & 47.55 \\
\hline & Yellow & 94.69 & -5.88 & 82.18 & 94.10 & -20.86 & 96.47 & 99.80 & -10.62 & 110.48 & 97.38 & -15.30 & 84.40 \\
\hline & Green & 40.60 & -43.18 & 5.26 & 45.65 & -42.24 & 22.53 & 46.92 & -48.25 & 14.05 & 48.40 & -37.99 & 14.94 \\
\hline & Blue & 38.78 & 3.07 & -43.18 & 33.61 & 32.30 & -58.59 & 40.64 & 11.41 & -54.83 & 41.92 & 16.15 & -49.59 \\
\hline
\end{tabular}


$<$ Table 5> Fabric colors of polyester through naked eyes and the smartphones

\begin{tabular}{c|c|c|c|c}
\hline & Through naked eyes & $\begin{array}{c}\text { LG } \\
(\mathrm{G} 2)\end{array}$ & $\begin{array}{c}\text { Samsung } \\
\text { (Galaxy S4 LTE-A) }\end{array}$ & $\begin{array}{c}\text { Apple } \\
\text { (i phone 5s) }\end{array}$ \\
\hline Red & & & & \\
\hline Yellow & & & & \\
\hline Green & & & & \\
\hline Blue & & & & \\
\hline
\end{tabular}

$<$ Table 6> Fabric colors of wool through naked eyes and the smartphones

\begin{tabular}{c|c|c|c|c}
\hline & Through naked eyes & $\begin{array}{c}\text { LG } \\
(\mathrm{G} 2)\end{array}$ & $\begin{array}{c}\text { Samsung } \\
\text { (Galaxy S4 LTE-A) }\end{array}$ & $\begin{array}{c}\text { Apple } \\
\text { (i phone 5s) }\end{array}$ \\
\hline Red & & & & \\
\hline Yellow & & & & \\
\hline Green & & & & \\
\hline Blue & & & & \\
\hline
\end{tabular}

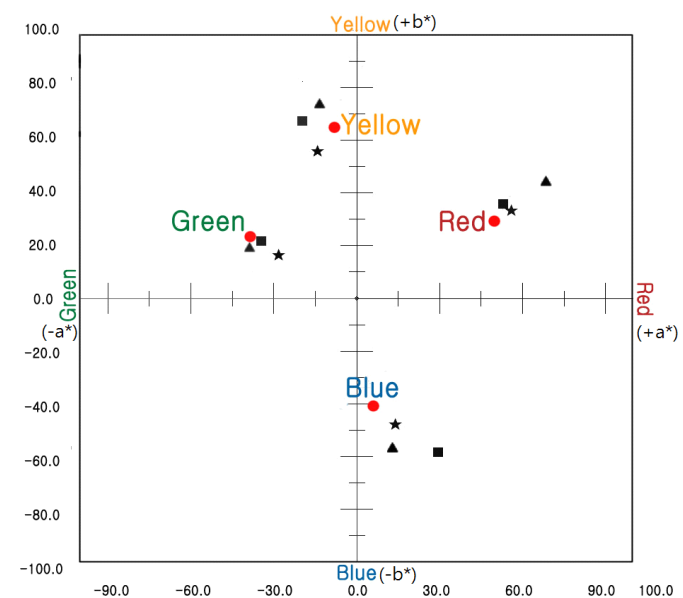

Naked eyes,

$\boldsymbol{\Delta}:$ Samsung, $\star$ : Apple,

LG

<Fig. 2> Color coordinate of the polyester fabrics

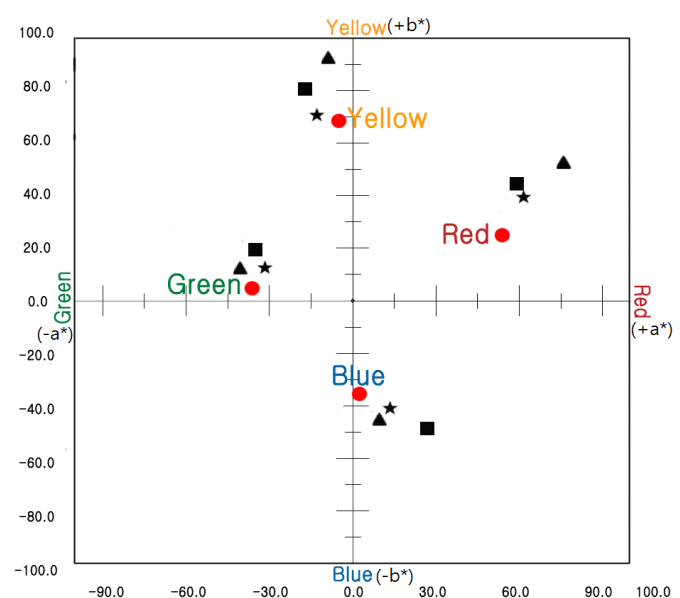

Naked eyes, $\boldsymbol{\Delta}$ : Samsung, $\star$ : Apple,

LG

<Fig. 3> Color coordinate of the wool fabrics 
특히 Samsung사와 LG사가 유사하였다. 파란색은 스 마트폰 직물 색상의 b*가 '-’경향을 보이고 있었으며, $\mathrm{LG}$ 사가 가장 큰 차이를 나타났다.

양모 직물 또한 모든 색상에서 스마트폰 직물과 실 제 직물과의 색상 차이가 나타났으며, 폴리에스터 직 물보다 전반적으로 차이가 더 크게 나타났다. 색상별 로 살펴보면, 빨간색은 스마트폰 직물의 $\mathrm{a}$ *가 '+'경향 을 보이고 있었으며, 타 스마트폰에 비해 $\mathrm{S}$ 사가 실제 직물보다 선명한 빨간색으로 나타났다. 노란색은 스 마트폰 직물의 b*가 ‘+'경향을 보이고 있어 실제 직 물보다 노란색을 선명하게 표현하고 있었다. 양모직물 역시 초록색에서 스마트폰 직물과 실제 직물의 색상 이 가장 유사하게 나타났다. 파란색은 스마트폰 직물 색상의 b*가 '-'경향을 보이고 있었으며, $\mathrm{LG}$ 사가 가 장 크게 나타나 폴리에스터와 유사한 결과를 보였다.

직물 종류에 따른 색상 좌표를 세부적으로 분석한 결과, 폴리에스터 직물의 좌표는 빨간색에서 Samsung 사의 a*값이 가장 '+'로 나타나 실제 직물과 편차가 가장 컸다. 반면에, LG사와 Apple사는 상대적으로 실 제 직물과 편차가 적었으며, $\mathrm{LG}$ 사가 가장 실제 직물 과 유사하였다. 초록색의 경우는 Apple사의 $\mathrm{a}$ *가 가 장 ‘+'로 나타나 실제 직물과의 색상 차이가 가장 컸 으며, Samsung사와 LG사는 실제 직물과 색상차이가 상대적으로 작았다. 또한, Samsung사의 $\mathrm{a}$ *값이 가장 ‘-’로 나타나 채도가 가장 높았다. 노란색도 Samsung

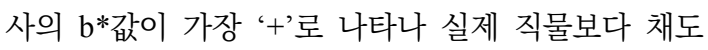
를 높게 표현해 주고 있었지만, 반면에 파란색만 LG 사의 $\mathrm{b}$ *값이 가장 '-’로 파란색 채도가 높게 나타나, 다른 색과 상이한 결과를 보였다.

종합해 보았을 때 Samsung 스마트폰이 타 스마트 폰에 비해 채도가 높은 것으로 확인할 수 있었다. 이 는 Samsung의 화면 색재현율이 타 스마트폰 화면에 비해 높기 때문에 채도가 높게 표현되는 것으로 볼 수 있다(Kim, Shin, \& Lee, 2014). 그러나 파란색에서 만 LG 스마트폰이 높았는데, 이는 화면의 색온도가 타 화면보다 높았기 때문으로 판단되며, 향후 세부적인 추적 연구가 필요한 부분이다.

폴리에스터 직물의 색좌표(Fig. 2) 결과는 양모 직 물 색좌표(Fig. 3)의 경향과 유사하였다. 실제 직물의 종류와 특성이 다르기 때문에 좌표의 위치는 동일하 지 않았지만, 각 스마트폰 좌표의 위치가 폴리에스터
결과와 유사하게 나타난 것으로 보았을 때 직물의 종 류가 변해도 실제 직물의 색을 나타내는 경향이 유사 한 것으로 판단할 수 있다. 또한, 양모 직물도 빨강, 노랑, 초록에서 Samsung사의 채도가 가장 높았으며, 파란색에서만 $\mathrm{LG}$ 사가 가장 높게 나타나 폴리에스터 직물과 동일한 결과를 보였다.

결과를 종합해 보았을 때 스마트폰으로 보이는 폴 리에스터 직물과 양모 직물의 색상 측정 결과, 각각 의 스마트폰의 $a * b *$ 색좌표 위치가 유사하게 분포하 고 있는 것으로 나타났다. 이것은 스마트폰으로 직물 을 볼 때 직물 종류가 달라지더라도 같은 색상 계열 에서는 유사한 분포를 나타나 일관성을 보이는 것으 로 판단할 수 있다. 그러나 좌표분포 위치는 직물 종 류에 따라 상이했는데, 노란색 폴리에스터 직물은 스 마트폰 색상좌표가 실제 직물의 왼쪽에 분포하고 있 었지만, 양모 직물은 상단에 분포하였다. 한편, 초록 색 폴리에스터 직물의 경우, 스마트폰 색상 좌표가 실제 직물 기준으로 하단에 분포하고 있었지만, 양모 직물은 상단에 분포하고 있었다.

\section{Comparison of fabric color difference through} naked eyes and the smartphones

〈Fig. 2〉와 〈Fig. 3〉을 통하여, 직물의 색상 $\left(\mathrm{a}^{*} \mathrm{~b}^{*}\right)$ 경향은 확인할 수 있지만, 명도를 나타내는 $\mathrm{L}^{*}$ 값이 반영되지 않은 자료기 때문에 직물간의 정확한 색차 $(\Delta \mathrm{E})$ 는 알 수 없었다. 따라서 실제 직물과 스마트폰 직물의 색차를 비교하기 위해 색상평가 자료를 이용 하여 수식에 의하여 색차 $(\Delta \mathrm{E})$ 를 구하여 〈Table 7〉에 나타내고, 그래프로 비교분석하였다(Fig. 4, Fig. 5).

\section{1) Color differences of polyester fabrics}

실제 육안으로 보는 폴리에스터 직물과 각각의 스 마트폰으로 보이는 직물의 색차를 직물색 별로 정리 하여 그래프로 나타내었다(Fig. 4). 스마트폰 모델별 로 그래프 색을 다르게 하여 구분하기 용이하게 하였 고, 왼쪽은 'LG' 스마트폰, 가운데는 'Samsung', 오른 쪽은 'Apple'을 나타낸다. 각각의 그래프 상단에 위치 한 수치는 실제 직물 색과 스마트폰으로 보이는 직물 색의 색차이다.

기기 분석에 의한 색 측정 결과, 직물색에 따라 스 마트폰의 색표현 정도가 상이함을 알 수 있었다. 빨 
<Table 7> Fabric color difference through naked eyes and the smartphones

\begin{tabular}{c|c|c|c|c|c|c}
\hline \multicolumn{1}{|c|}{ Fiber } & \multicolumn{2}{c}{ Polyester } & \multicolumn{3}{c}{ Wool } \\
Color & $\begin{array}{c}\text { LG } \\
(\mathrm{G} 2)\end{array}$ & $\begin{array}{c}\text { Samsung } \\
\text { (Galaxy S4 LTE-A) }\end{array}$ & $\begin{array}{c}\text { Apple } \\
(\mathrm{i} \text { phon5s) }\end{array}$ & $\begin{array}{c}\text { LG } \\
(\mathrm{G} 2)\end{array}$ & $\begin{array}{c}\text { Samsung } \\
\text { (Galaxy S4 LTE-A) }\end{array}$ & $\begin{array}{c}\text { Apple } \\
(\mathrm{i} \text { phon5s) }\end{array}$ \\
\hline Red & 8.87 & 30.11 & 10.15 & 23.79 & 42.89 & 20.42 \\
\hline Yellow & 14.71 & 13.73 & 13.57 & 20.72 & 29.14 & 10.05 \\
\hline Green & 8.78 & 12.73 & 18.40 & 18.02 & 11.96 & 13.47 \\
\hline Blue & 35.65 & 22.28 & 16.58 & 33.44 & 14.45 & 14.90 \\
\hline
\end{tabular}

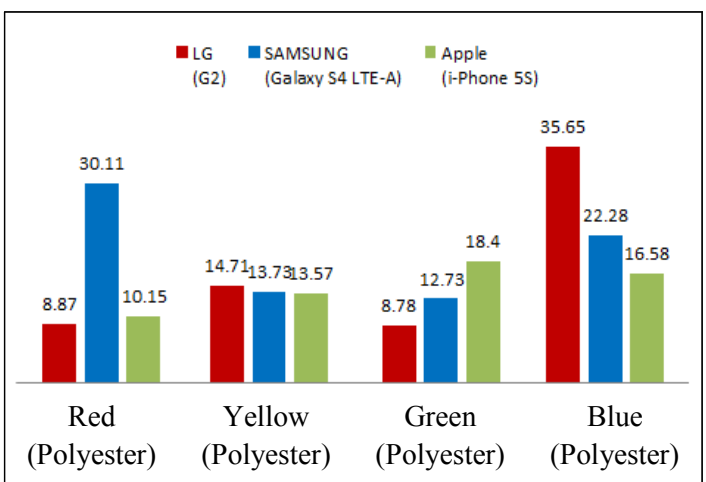

<Fig. 4> Colors differences of polyester fabrics through naked eyes and the smartphones

간색의 경우, Samsung이 노란색과 파란색은 LG가 실 제 직물 색과 가장 색차가 크게 나타났으며, 초록색 은 Apple이 가장 크게 나타났다. 4가지 색 중에 노란 색은 스마트폰 별로 색차가 1 이내로 편차가 미미한 것으로 나타나 유사한 색을 보여주고 있었지만, 파란 색의 경우는 스마트폰 별로 색차가 가장 크게 나타났 다. 또한 빨간색의 경우 Apple과 LG 스마트폰은 편 차가 육안으로 구별할 수 없는 범위인 1.5 이내인 반 면 Samsung 스마트폰이 가장 큰 색차를 보이고 있음 을 알 수 있다.

\section{2) Color differences of wool fabrics}

양모 직물 또한 직물 색에 따라 스마트폰의 색차가 상이함을 알 수 있었는데, 폴리에스터와 유사한 결과 를 보여주고 있었다(Fig. 5). 빨간색의 경우는 Samsung이 가장 큰 색차를 나타내고 있었으며, 노란색은 Apple이 실제 직물 색과 가장 색차가 크게 나타났다. 초록색은 LG가 가장 크게 나타났으며, 파란색의 경

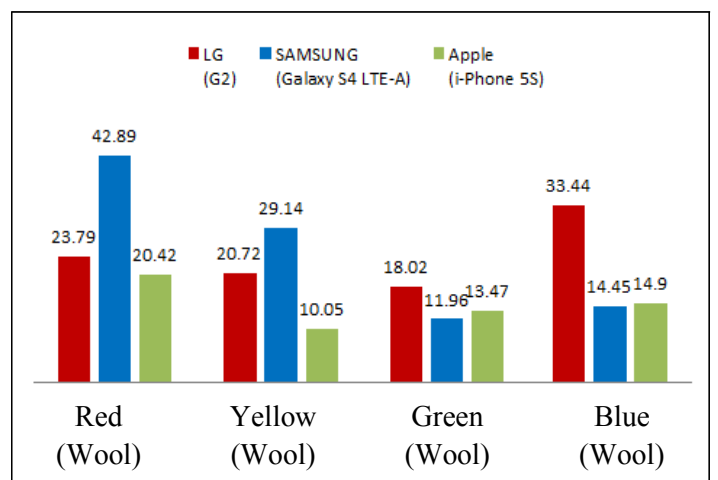

<Fig. 5> Colors differences of wool fabrics through naked eyes and the smartphones

우 Samsung과 Apple은 색차가 유사한 반면, LG의 색 차는 크게 나타났다.

또한 실제 직물을 기준으로 $\mathrm{L}$ *값을 비교해본 결 과, $\mathrm{LG}$ 가 실제 직물과의 편차가 6 이내로 가장 유사 하게 나타났으며, Samsung과 Apple은 실제 직물과 편차가 10 이내로 나타났다. $\mathrm{a}^{*}$ 와 $\mathrm{b}^{*}$ 값은 실제직물과 스마트폰과의 차이가 *L값에 비해서 편차가 크게 나 타났는데, 특히 빨간색의 경우 *b값은 20 까지 차이가 나타났다.

종합해 보았을 때, 모든 스마트폰에서 실제직물과 뚜렷한 색차(폴리에스터 직물: 8 이상, 양모 직물: 10 이상)를 나타내었으므로 모바일 폰 쇼핑에서 소비자 불만의 요소를 가지고 있다고 판단할 수 있다.

\section{N. Conclusion and Suggestion}

본 연구는 실제 육안으로 보는 폴리에스터와 양모 두 직물의 색상과 LG, Samsung, Apple사에서 제조한 
세 종류 스마트폰 화면으로 보여지는 빨강, 노랑, 초 록, 파랑 네 직물의 색상과 색차를 전문 측정기기를 이용하여 측정 후, 정량적 수치로 비교 분석하여 얻 은 결과를 통하여 다음과 같은 결론을 도출하였다.

첫째, 스마트폰으로 보이는 직물 두 종류의 색상을 측정한 결과, 각각의 스마트폰 직물색의 색좌표 위치 가 폴리에스터와 양모직물의 종류와 상관없이 유사 하게 분포하고 있는 것으로 나타났다. 스마트폰으로 직물을 볼 때 직물 종류가 달라지더라도 같은 색상 계열에서는 유사한 분포를 보이므로, 모바일 쇼핑 시 에 직물 종류에 따른 색상 불일치 문제는 크게 발생 하지 않을 것으로 본다.

둘째, 스마트폰 세 종류에 따른 직물의 네 가지 색 상을 측정한 결과, Samsung 스마트폰은 색재현율이 타 스마트폰보다 높아서 직물의 종류에 상관없이 빨 강, 노랑, 초록에서 채도가 높게 나타났으며, 특히 빨 간색에서 타 스마트폰에 크게 나타났다. 파란색은 색 온도가 가장 높았던 LG 스마트폰의 채도가 높게 나타 났다. 이는 스마트폰의 종류에 따라, 그리고 직물색의 종류에 따라서 색상 차이가 존재하므로 모바일 쇼핑 시 색상 불일치에 대한 고려를 염두해 두어야 한다.

셋째, 실제 직물과 스마트폰 직물과의 색차를 비교 해본 결과, 색상측정 결과와 동일하게 나타났으며, 특 히 Samsung 스마트폰은 빨간색 양모와 폴리에스터 직물에서 실제 직물과의 색차가 크게 나타났으며, $\mathrm{LG}$ 스마트폰은 파란색에서 크게 나타났다. 색차 9-43 사 이의 범위는 현저하게 색상 차이가 나는 것으로 모바 일 쇼핑 구매자의 불만족을 발생시키는 위험 요소이다. 연구 결과에 대한 제언은 다음과 같다. 기기분석 결 과, 스마트폰 별 색상 차이가 존재하였으며, 이는 화 면 색 재현율이 큰 요인으로 판단된다. Samsung 스마 트폰은 LG와 Apple에 비해 색재현율이 컸기 때문에 전반적으로 채도가 높게 나타났는데, 현재 Samsung 스마트폰은 색재현율을 낮춘 화면 옵션을 제공하고 있어 사용자가 보다 정확한 색상옵션으로 변경하여 사용할 수 있지만, 이 옵션도 표준 규격보다 높은 색 재현율을 보이기 때문에, 제조사는 표준 규격에 맞는 색재현 옵션을 제공할 필요가 있다.

향후 새로운 스마트폰이 끊임없이 개발될 것이고, 모바일 쇼핑 규모 역시 지속적으로 성장할 것으로 예 측되기 때문에, 모바일 쇼핑 문제점의 개선에 대한
꾸준한 연구가 필요하다. 특히 모바일 쇼핑은 시각으 로만 제품을 판단해야 하는 한계점이 존재하기 때문에, 소비자 불만을 감소시키기 위해서 상품 판매자 또는 업체는 직물 종류와 색상에 따른 정확한 제품 색상에 관한 추가적인 정보를 소비자에게 제공해야 할 것이 며, 스마트폰 제조사는 밝기 조절, 화면 색재현율 옵 션 등의 세부적인 옵션과 설명을 제공하여야 한다.

본 연구의 제한점으로는 색상의 기기분석을 위하 여, 실제 직물과 스마트폰에 보여지는 직물을 카메라 로 촬영하여 스마트폰으로 구현했기 때문에, 동일조건 에서 촬영했으나 촬영도구에 따라 색상 표현이 다를 수 있으므로, 후속연구에서 피시험자를 대상으로 관 능평가를 실시하여, 실제 육안으로 보는 색과 스마트 폰으로 보여지는 색의 비교 분석을 진행하였다. 또한 사용한 직물과 섬유가 두 종류이므로 모든 직물에 확 대해석하기에는 무리가 있으므로, 후속연구에서는 다 양한 직물과 섬유를 대상으로 하는 연구가 요구된다.

\section{References}

ATLAS Research \& Consulting. (2014, February 10). 2013년 국내 휴대폰 판매 동향 [2013 smartphone sales trends in Korea]. Retrieved May 26, 2014, from http://www.arg.co.kr/atlas/client/html/article/ article_info.html?type_seq $=18 \&$ content_seq $=59454$

Cho, Y. J., Lim, S. J., \& Lee, S.-H. (2001). Apparel purchase behavior among internet shoppers: Focusing on perceived risks. Journal of the Korean Society of Clothing and Textiles, 25(7), 1247-1257.

Choi, N.-Y., \& Lee, J.-S. (2006). The subjective evaluation of color image depending on the change of luminous source. Fashion \& Textile Research Journal, 8(6), 721-726.

Kim, H. S., Shin, S. K., \& Lee, Y. H. (2014). A comparative study of improved color reproduction for the latest smartphone displays based on AMOELD and TFT-LCD. AURA, 32, 158-174.

Kim, M. J. (2012). A study on adolescents' clothing purchasing behavior in internet shopping mall and clothing shopping orientation. Unpublished master's thesis, Kongju National University, Kongju, 
Korea.

Kim, S. Y. (2007). A study on the quality characteristics for the satisfaction of customers purchasing clothes in internet shopping malls: Focused on Kano's theory. Unpublished master's thesis, Hanyang University, Seoul, Korea.

Korean Agency for Technology and Standards. (2009). 공공디자인 색채표준 가이드 [Public design color standard guide]. Seoul: Korean Standards Association.

Korean Agency for Technology and Standards. (2010). Name of non- luminous object colours (Standard No. KS A 0011). Retrieved from https://standard. go.kr

Korea Customer Agency. (2005). 사이버 쇼핑몰 의류 상품정보의 신뢰성과 품질 [Reliability and quality of cyber shopping mall's clothing information]. Retrieved May 26, 2014, from http://www. kca.go.kr/brd/m_32/down.do?brd_id=G004\&seq= $659 \&$ data $t p=A \&$ file $s e q=1$

Lee, E. J. (2013). A study on color appearance of clothing under store lighting of variable color temperatures and various illuminances: Focusing on ambient lighting. Journal of Korea Society of Color Studies, 27(4), 49-57.

Park, J. H., \& Stoel, L. (2002). Apparel shopping on the internet: Information availability on US apparel merchant web sites. Journal of Fashion Marketing and Management: An International Journal, 6(2), 158-176. doi:10.1108/13612020210429908

Park, T.-Y., Lee, C.-H., \& Ha, Y.-H. (2008). Evaluation of color reproduction characteristics of TFTLCD and AMOLED for mobile phone. Journal of the Institute of Electronics Engineering of Korea $S P, 45(1), 29-37$.

Statistics Korea. (2014). Report of online shopping survey in the first quarter 2014. Daejeon: Author.

The Korea Chamber of Commerce \& Industry. (2013, August 23). 모바일·인터넷쇼핑 소비자 동향조사 [The trend report of mobile and internet shopper]. Retrieved May 26, 2014, from http://www.korcham.net/nCham/Service/Economy/appl/KcciRepo rtDetail.asp?SEQ NO C010 $=20120927307 \&$ CHA $\mathrm{M} \mathrm{CD}=\mathrm{B} 001$

Yoh, E. A. (2011). Effect of color sensibility evaluation of clothing product on attitude toward product in on-line and off-line: Focusing on white T-Shirt. The Research Journal of the Costume Culture, 19(3), 650-660.

Yun, H.-K., \& Kweon, S.-A. (2003). Actual usage, clothing purchasing behavior and recognition toward internet fashion shopping mall of university students. Korean Journal of Human Ecology, 12 (2), 225-236. 